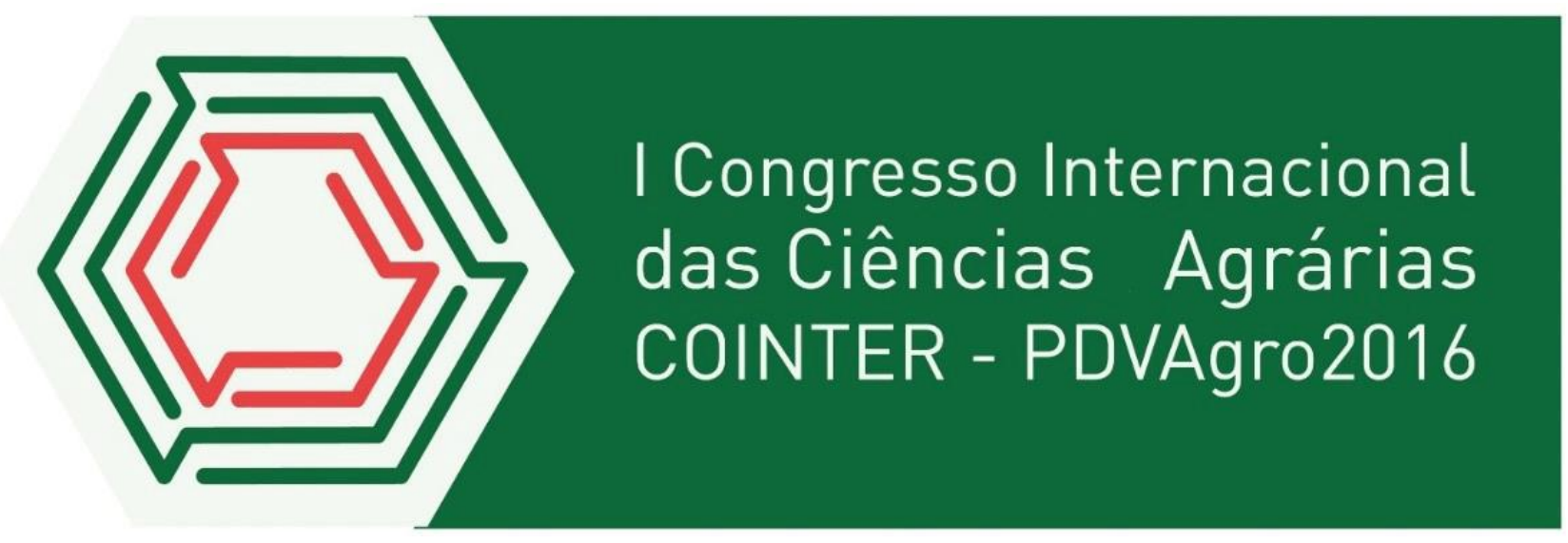

\title{
USO DE ARMADILHAS ALTERNATIVAS PARA O MONITORAMENTO DE ADULTOS DE MOSCAS-DAS-FRUTAS (Anastrepha spp.) EM POMAR DE ACEROLA
}

\author{
Apresentação: Pôster
}

\begin{abstract}
Alef John Félix da Silva ${ }^{1}$; Anderson Ricardo Galdino da Silva²; Fábio José Marques ${ }^{3}$; José Maciel da Silva ${ }^{4}$; Pablo Radamés Cabral de França ${ }^{5}$
\end{abstract}

\section{Introdução}

A aceroleira (Malpighia emarginata DC., Malpighiaceae) é uma planta de porte arbustivo, rústica, muito cultivada no Brasil, principalmente na região nordeste, sendo atualmente considerada importante frutífera tropical (GUEDES et al., 2011). Essa fruta tem atraído o interesse dos agricultores devido ao elevado teor de vitamina $\mathrm{C}$, com conteúdo de ácido ascórbico variando de 695 a $4827 \mathrm{mg} .100 \mathrm{~g}^{-1}$ de polpa (MEZADRI et al., 2006). Este atributo proporcionou que a fruta fosse amplamente utilizada na alimentação humana e na fabricação de produtos farmacêuticos além de atender o mercado de polpa processada e fruta in natura.

Dentre os principais tratos fitotécnicos aplicados nas frutíferas, o manejo de pragas consiste em uma etapa crucial para o sucesso do produtor, haja vista que dependendo da praga e o tipo de dano provocado, além das perdas, podem ocorrer uma limitação de comercialização dos frutos. Fato que pode ocorrer em várias frutíferas quando atacadas por moscas-das-frutas, pragas, que constituem uma das principais barreiras fitossanitárias à exportação, em função das restrições quarentenárias impostas pelos mercados importadores de frutas "in natura" (MALAVASI et al., 1980).

\footnotetext{
${ }^{1}$ Agronomia, IFPE campus Vitória de Santo Antão, alefjohn.aj@gmail.com

${ }^{2}$ Agronomia, IFPE campus Vitória de Santo Antão, andersonrgs2013@gmail.com

${ }^{3}$ Me. em Agronomia, IFPE campus Vitória de Santo Antão, fabio.marques@vitoria.ifpe.edu.br

${ }^{4}$ Agronomia, IFPE campus Vitória de Santo Antão, j.maciel.93@gmail.com

${ }^{5}$ Dr. em Agronomia, IFPE campus Vitória de Santo Antão, pabloradames@hotmail.com
} 
No Manejo Integrado de Pragas (MIP), o monitoramento é umas das etapas mais importantes para a tomada de decisão sobre medidas de controle, pois a partir dele é possível definir os níveis populacionais. Para as moscas das frutas uma das alternativas mais utilizadas para o monitoramento são as armadilhas. Estas, que na maioria das vezes são adquiridas em casas comerciais associadas à feromônios e/ou atrativos alimentícios, onde se destacam os modelos McPhail e Jackson. Entretanto, algumas alternativas de menor custo e praticidade têm sido testadas para o monitoramento de moscas das frutas.

Objetivou-se com o trabalho testar uma armadilha alternativa para o monitoramento da densidade populacional de moscas das frutas em um pomar de Acerola durante a entressafra da cultura.

\section{Fundamentação Teórica}

A acerola é conhecida no Brasil há mais de 50 anos, mas o seu cultivo em escala comercial data de meados dos anos 80. Esta frutífera, por ser uma expressiva fonte de vitamina C, atraiu o interesse de pesquisadores, extensionistas, produtores e empresários do agronegócio que passaram a investir as suas ações não somente em culturas já consolidadas como o abacaxi, a banana, a laranja, o caju e o coco (CARVALHO e MANICA, 1993). Esta frutífera pode florescer e frutificar várias vezes durante o ano, conforme as condições meteorológicas locais, podendo chegar ate nove safras/ ano em regiões tropicais. Fato, que confere uma vantagem para o produtor, haja vista a possibilidade de oferta do produto o ano todo. No caso da região semiárida tropical do Nordeste do Brasil, a produção no período seco depende da utilização de irrigação.

A distribuição das moscas-das-frutas está diretamente relacionada aos seus hospedeiros. Esse fato dificulta muito o controle, já que as moscas possuem vasta gama de hospedeiros, os quais, muitas vezes, são nativos. Os danos diretos devem-se ao fato das moscas adultas ovipositarem no interior dos frutos, dando origem às larvas que se alimentam da polpa. Já os danos indiretos devemse às barreiras fitossanitárias impostas pelos países importadores de frutas in natura, como os EUA e Japão (DUARTE e MALAVASI, 2000). As moscas-das-frutas são uma preocupação constante dos países livres dessas pragas, os quais investem bastante na proteção de sua agricultura, impondo severas restrições às importações de frutas frescas de países onde estas pragas ocorrem.

O controle racional e eficiente das moscas-das-frutas tem como pré-requisito o monitoramento populacional de adultos que permite o acompanhamento da flutuação da praga em uma determinada área, ou a detecção de espécies exóticas ou quarentenárias, possibilitando 
caracterizar a população dos tefritídeos do ponto de vista qualitativo e quantitativo (NASCIMENTO et al., 2000).

Os dados de monitoramento representam a realidade do campo e são utilizados para determinar o nível de controle, evitando as pulverizações de inseticidas baseadas apenas em calendário e com isso diminuindo o custo de produção e o nível de resíduos nos alimentos no ambiente (VIANA, 2009).

Mesmo na entressafra das frutíferas, as moscas-das-frutas ainda permanecem nas áreas de produção completando seu ciclo de vida nas plantas hospedeiras. Esses insetos são polífagos e em regra infestam mais de um hospedeiro. Segundo Zucchi (2000), através de levantamento realizado no Brasil foram registradas mais de 58 espécies de frutos hospedeiros, distribuídos em 21 famílias.

\section{Metodologia}

O trabalho foi realizado num pomar de acerola do IFPE campus Vitória de Santo Antão, durante 10 e 20 de junho de 2016. O município está localizado na mesorregião da Zona Mata e na Microrregião de Vitória de Santo Antão do Estado de Pernambuco (CPRM, 2005).

Para a confecção das armadilhas, utilizou-se garrafas PET, sendo feitas três perfurações de 2 x $2 \mathrm{~cm}$ na mesma altura e de maneira desencontrada, em garrafas de cor verde e transparente. Utilizou-se como atrativos alimentícios $500 \mathrm{ml}$ de suco concentrado de acerola e goiaba (Psidium guajava L.) adoçado com $30 \mathrm{~g}$ de açúcar refinado. As garrafas foram postas numa altura de 1,5 m do solo, localizadas no terço médio da planta, sempre nas bordas dos blocos. As armadilhas foram mantidas durante 12 dias e monitoradas a cada três dias. Em cada verificação formam coletadas as moscas das frutas presentes nas armadilhas, seguido da separação por sexo.

O delineamento utilizado foi em blocos casualizados com 4 tratamentos e 3 blocos. Sendo os tratamentos: $\mathrm{T} 1$ = garrafa transparente e suco de acerola; $\mathrm{T} 2$ = garrafa transparente e suco de goiaba; T3 = garrafa verde e suco de acerola e T4 = garrafa verde e suco de goiaba. Os dados foram submedito a análise de variância e teste de Scott-Knott para comparação de médias.

\section{Resultados e Discussões}

Durante o período de avaliação foram capturados 140 indivíduos de Anastrepha spp, sendo 52 machos e 88 fêmeas. Na figura 1, observa-se a média do número de indivíduos por tratamento e dividido por sexo (macho/fêmea). Nota-se que em todos os tratamentos houve um número maior de fêmeas em detrimento dos machos. No uso de atrativos alimentícios, normalmente as fêmeas são mais atraídas devido à necessidade nutricional para produção de ovos (ZUCOLOTO, 2000). O suco 
de goiaba apresentou os melhores resultados na captura de Anastrepha spp tanto para a garrafa transparente (T2) quanto para a verde (T4), sendo o tratamento 2 superior estatisticamente ao 4. Comparando-se a cor da garrafa PET, constatou-se que para os dois tipos de atrativos (sucos) a transparente apresentou os melhores resultados. Em alguns casos o tipo de cor da armadilha influência na captura de moscas das frutas. Sobrinho et al. (2001), recomendou em seu trabalhos o uso de armadilhas amarelas para o monitoramento de moscas do gênero Anastrepha. Já Adamuchio et al. (2008), não constatou diferença estatística no uso de armadilhas de base amarela em detrimento das totalmente transparente.

No controle por comportamento existem armadilhas e atrativos alimentícios comerciais que são recomendados para a captura de mosca-das-frutas, porém na maioria das vezes onera muitos custos para o pequeno produtor, limitando o seu acesso. Neste trabalho foi possível obervar que o uso de armadilhas alternativas feitas com o reuso de garrafas PET e sucos de frutas, podem ser uma ótima alternativa para a captura e monitoramento de mosca-das-frutas, em detrimento das armadilhas e atrativos comerciais.

Figura 1: Média da densidade populacional de Anastrepha spp por tratamento. Onde: T1 = garrafa transparente e suco de acerola; T2 = garrafa transparente e suco de goiaba; T3 = garrafa verde e suco de acerola e T4 = garrafa verde e suco de goiaba. (Scott-Knott 5\%. Médias seguidas de mesma letra não apresentam diferença estatística). Fonte: Própria.

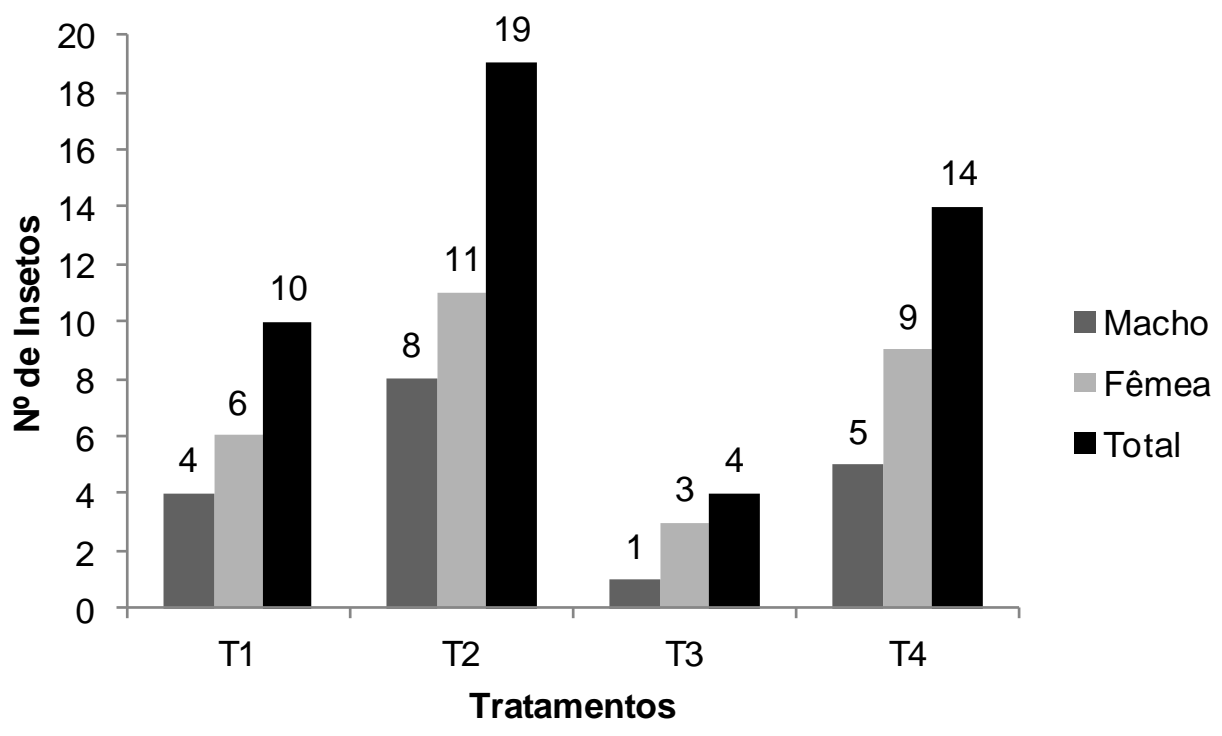

\section{Conclusões}

Com base no experimento realizado recomenda-se o uso de suco de goiaba associado à garrafa PET transparente como alternativa para o monitoramento de moscas das frutas em pomares 
de acerola.

\section{Referências}

ADAMUCHIO, J. G.; SHUBER, J. M.; CARDOSO, N. A.; PASTORI, P. L.; PALTRONIERI, A. S. Influência da cor em armadilhas modelo Mcphail para atração de mosca-das-frutas em pomares de Pessegueiro. Caatinga (Mossoró,Brasil), v.21, n.3, p.124-127, 2008

CARVALHO, R.I.N de; MANICA, I. Acerola: composição e armazenamento de frutos. Porto Alegre: UFRGS, 1993. 7p. (Cadernos de Horticultura, 1)

CPRM. Mascarenhas, JC; Beltrão, BA; Souza Junior, LC; Galvão, MJTG; Pereira, SN; Miranda, JLF. Projeto cadastro de fontes de abastecimento por água subterrânea. Diagnóstico do município de Vitória de Santo Antônio, estado de Pernambuco. 22p. il. 2005.

DUARTE, A.L.; MALAVASI, A. Tratamentos Quarentenários. In: MALAVASI, A.; ZUCCHI, R.A. (Ed.). Moscas-das-frutas de importância econômica no Brasil, conhecimento básico e aplicado. Ribeirão Preto: Holos Editora, 2000. Cap. 25, p.187-192.

GUEDES, R. S.; ZANELLA, F. C. V.; MARTINS, C. F.; SHLINDWEIN, C. Déficit de Polinização da aceroleira no período seco no semiárido paraibano. Rev. Bras. Frutic., Jaboticabal, SP, v.33, n.2, p.465-471, 2011.

MALAVASI, A.; MORGANTE, J.S.; ZUCCHI,R.A., Biologia de "moscas-das-frutas" (Diptera, Tephritide) : Lista de hospedeiros e ocorrência. Rev. Brasil Biol. 40(1): 9-16, 1980.

MEZADRI, T.; FERNÁNDEZ-PACHÓN, M.S.; VILLAÑO, D.; GARCÍA-PARRILLA, M.C.; TRONCOSO, A.M. El fruto de la acerola: composición, características productivas e importancia económica. Archivos Latinoamericanos de Nutrición, v.56, p.101-109, 2006.

NASCIMENTO, A.S.; CARVALHO, R. da S.; MALAVASI, A., Monitoramento populacional. In: MALAVASI, A; ZUCCHI, R.A. (Eds.) Moscas-das-frutas de importância econômica no Brasil conhecimento básico e aplicado. Ribeirão Preto: Holos, p.109-112, 2000.

SOBRINHO, R. B.; MALAVASI, A.; OMETO, A. C. F. Manual operaciona para levantamento, detecção, monitoramento e controle de mosca-das-frutas. EMBRAPA Agroindustrial tropical, Circular técnica n. 9, p.29, maio, 2001.

VIANA, R.E, Fenologia Do Fruto de Aceroleiras nas Condições do Vale Do São Francisco. Juazeiro-BA,Projeto FAPESB, 2009.

ZUCCHI, R. A., Espécies de Anastrepha, Sinonímias, Plantas Hospedeiras e Parasitóides. In: MALAVASI, A.; ZUCCHI, R. A. (Ed.). Moscas-das-frutas de importância econômica no Brasil: conhecimento básico e aplicado, Cap. 4, p. 41-48 Ribeirão Preto: Holos, 2000.

ZUCOLOTO, F.S. Alimentação e nutrição de moscas-das-frutas. In: MALAVASI, A.; ZUCCHI, R.A. (Ed.). Moscas-das-frutas de importância econômica no Brasil: conhecimento básico e aplicado. Ribeirão Preto: Holos, 2000. 327p. 